Cross-cultural verbal deception

\title{
Cross-cultural verbal deception
}

\author{
Sharon Leal \\ Aldert Vrij \\ Zarah Vernham \\ Gary Dalton \\ Louise Jupe \\ Adam Harvey \\ Department of Psychology, University of Portsmouth \\ Galit Nahari \\ Department of Criminology, Bar Ilan University
}

Author notes

This work was funded by the Centre for Research and Evidence on Security Threats (ESRC Award: ES/N009614/1)

Correspondence concerning this article should be addressed to Sharon Leal, Department of Psychology, University of Portsmouth, King Henry Building, King Henry 1 Street, PO1 2DY, Hants, United Kingdom. Email: sharon.leal@port.ac.uk 
Cross-cultural verbal deception

Abstract

Background. 'Interviewing to detect deception' research is sparse across different ethnic groups. In the present experiment, we interviewed truth tellers and liars from British, Chinese and Arab origins. British interviewees belong to a low-context culture (using a communication style that relies heavily on explicit and direct language), whereas Chinese and Arab interviewees belong to high-context cultures (communicate in ways that are implicit and rely heavily on context).

Method. Interviewees were interviewed in pairs and 153 pairs took part. Truthful pairs discussed an actual visit to a nearby restaurant, whereas deceptive pairs pretended to have visited a nearby restaurant. Seventeen verbal cues were examined.

Results. Cultural cues (differences between cultures) were more prominent than cues to deceit (differences between truth tellers and liars). In particular, the British interviewees differed from their Chinese and Arab counterparts and the differences reflected low and high context cultures communication styles.

Conclusion. Cultural cues could quickly lead to cross-cultural verbal communication errors: The incorrect interpretation of a cultural difference as a cue to deceit.

Keywords: deception, verbal cues to deceit, collective interviewing, low-context culture, high-context culture 
Cross-cultural verbal deception

\section{Cross-cultural verbal deception}

Research examining interview techniques to detect deception has typically been conducted in the USA and Western Europe. However, investigators across the world are often interested in how these research findings travel across cultures: Are they culturally specific or can they be generalised across cultures? To answer this question, cross-cultural research is required. In the present experiment, we examined verbal cues to deceit amongst three different cultures: British, Chinese and Arab.

In cross-cultural deception research, we can distinguish between cross-cultural cues and cues to deceit. Cross-cultural cues refer to differences between cultures and cues to deceit refer to differences between truth tellers and liars. An interaction between the two types of cue would result in culturally specific cues to deception. To give an example from an examination of gestures amongst native (white) and non-native (black) Dutch citizens, research has shown that black Dutch citizens make more gestures than white Dutch citizens (Vrij \& Winkel, 1991), which makes 'an increase in gestures' a cross-cultural cue. Research has further shown that in both white Dutch citizens and black Dutch citizens, liars tend to make fewer gestures than truth tellers (Vrij \& Winkel, 1991), which makes 'fewer gestures' a cue to deceit. Finally, since this decrease in gestures in liars occurred in both black and white Dutch citizen, gestures was not a culturally specific cue to deceit. We will keep this distinction between cross-cultural cues, cues to deceit and culturally specific cues to deceit in this article examining speech content.

Cross-cultural research examining verbal cues to deception is sparse, but the work of Taylor and colleagues is a noteworthy exception (Taylor, Larner, Conchie, \& Menacere, 2017; Taylor, Larner, Conchie, \& van der Zee, 2014). They examined verbal cues to deception amongst several cultural groups: Arab, Pakistani, North African, South Asian, White British and White European. It was found that a decrease in first person pronouns as a sign of deceit 
Cross-cultural verbal deception

was moderated by culture. That is, White British participants reduced their first person pronouns to the greatest extent and North African participants to the least extent, with White European and South Asian participants in between those two groups (Taylor et al., 2017). In Taylor et al. (2014) several culturally specific cues to deceit emerged. For example, the use of negations (e.g., denials) were indicative of deception in Arab and Pakistani populations, but not in White British and North African populations; and the use of spatial information was indicative of deception in North African and Pakistani populations but indicative of truth in Arab and White British populations.

A different line of research, not examined in the current experiment, is cross-cultural lie detection: The ability of people to recognise deception across cultures. A general finding in this -also sparse- line of research is that judgement accuracy tends to decrease when judgements are made across cultures (Bond \& Atoum, 2000; Bond, Omar, Mahmoud, \& Bonser, 1990). See Taylor et al. (2014) for a summary of this research.

\section{Cross-cultural cues}

A communication style is the way people communicate with others (Liu, 2016). Of the theoretical perspectives regarding cultural variations in communication styles, the mostly cited is Hall's (1976) distinction between high-context and low-context communication (Liu, 2016). Related to this distinction are distinctions between collectivistic cultures (highcontext communication) and individualistic cultures (low- context communication) and between indirect (high-context communication) and direct (low-context communication) speech (Liu, 2016). High-context and low-context cultures (Hall, 1976) are terms used to describe cultures based on how explicitly they exchange messages and how much the context means in the exchange of information. According to Hall (1976), messages exchanged in high-context cultures carry implicit meanings and rely heavily on context. In a higher-context culture, many things are left unsaid, letting the culture explain. Words and word choice 
Cross-cultural verbal deception

become important in higher-context communication, since a few words can communicate a complex message very effectively to an in-group member. In contrast, low-context cultures rely on explicit verbal communication. In a lower-context culture, it is important for the communicator to be explicit in order to be fully understood. This would imply that interviewees in low-context cultures will provide more information (to make the message understood), including references to their feelings, than interviewees in high-context cultures. Good examples of implicit high-context communication is that Koreans do not report pronouns when they speak (e.g. "I”, "We”), and that Chinese sometimes do not report tense when they speak (past, present, future), leaving it to the context to make this clear. Hall's high-context and low-context communication was inspired by Bernstein’s (1966) conceptualisation of restricted and elaborated codes (Liu, 2016). Restricted codes rely heavily on the hidden, implicit cues of the social context. The use of jargon, often used by doctors, psychologists, street gangs, family members etc., is an example of the use of restricted codes. The opposite are elaborate codes in which everything is explained and where context is not critical to understand what has been said (Liu, 2016). Copeland and Briggs (1986) provided an overview of how various countries could be defined in terms of high-context and lowcontext cultures. They rated the Chinese and Arab cultures as high-context cultures and the British culture as a low-context culture.

Collective interviewing -interviewing participants in pairs- enables interviewers to examine how group members communicate with each other while being interviewed. Based on the assumption that communication in low-context cultures is more explicit, it can be predicted that pairs belonging to low-context cultures communicate and interact more with each other (to make the meaning of the communication understood) than pairs belonging to high-context cultures. There are several field settings in which collective interviewing would be more suited than interviewing individuals separately, for example, during police stop and 
Cross-cultural verbal deception

searches, at road border controls where cars containing several people are checked, at security checkpoints (e.g., airports), during immigration interviews or during house-to-house enquiries. In such settings, it would be more timely and convenient to interview the group members simultaneously. See Vernham and Vrij (2015) for a review of collective interviewing research.

\section{Cues to deceit}

We examined various speech cues we thought were relevant for verbal lie detection. They were chosen for three different reasons. First, we examined speech cues that have been found to discriminate between truth tellers and liars in typical deception research in which Western participants are interviewed individually (e.g. number of details, checkable sources, expression of feelings). We were interested in whether these cues travel across cultures and are also diagnostic in collective interviewing. Second, we examined speech cues which are not often examined in deception research (e.g., lack of knowledge and expressing normality) but which we felt are relevant to examine, because they reveal potential verbal strategies liars use. Third, we examined speech cues that are relevant to examine in collective interviewing and which, theoretically, have potential to discriminate truth tellers from liars (e.g., interruptions, additions, posing questions to each other, providing cues to each other, the use of jokes).

Details. A consistent finding in deception research is that truth tellers typically provide more detail than liars (Amado, Arce, \& Fariña, 2015; DePaulo et al., 2003; Oberlader, Naefgen, Koppehele-Gossel, Quinten, Banse, \& Schmidt, 2016). Reasons for this are that liars lack the imagination and skills to convey the amount of detail that truth tellers convey (Vrij, 2008), or are reluctant to provide detail out of fear that such details may provide leads for investigators to check (Nahari, Vrij, \& Fisher, 2014a). In fact, 'total details' is amongst the most diagnostic verbal cues to deceit (Amado et al., 2015; Vrij, 2008). Since Taylor et al. 
Cross-cultural verbal deception

(2014) found that spatial information was indicative of truth in Arab and White British populations but indicative of deception in North African and Pakistani populations, we also broke down the total details variable in subcategories (visual, spatial, temporal, auditory information and actions) and explored the effects of Veracity and Ethic Group on these subcategories.

Verifiable sources. The Verifiability Approach (Nahari, 2017; Vrij \& Nahari, 2016; Vrij, Taylor, \& Picornell, 2015) predicts that truth tellers and liars report different types of detail. Central to the Verifiability Approach are two assumptions (Nahari, Vrij, \& Fisher, 2012, 2014a). First, to make an honest impression on interviewers, liars are inclined to provide many details. Second, liars prefer to avoid mentioning too many details out of fear that investigators can check such details and will discover that they are lying (Nahari et al., 2012). A strategy that compromises between these two conflicting motivations is to provide details that cannot be verified. Research has shown that liars report fewer details that can be checked (e.g., "I phoned my friend Fred at 10.30 this morning”) and more details that cannot be checked ("Several people walked by when I sat there”) than truth tellers (Vrij \& Nahari, 2016). Rather than counting the number of checkable details we counted the number of checkable sources (e.g. 'my friend Fred' in the example above). We did this for applied reasons, as checkable sources are probably easier to count in real time than checkable details. Checkable sources and checkable details are related to each other as a checkable source leads to checkable details.

Feelings. Liars often experience more negative affect than truth tellers (DePaulo et al., 2003; Mann, Vrij, Shaw, Leal, Ewens, Hillman, \& Granhag, 2013). Liars can feel guilty about lying or can be afraid of getting caught out (Ekman, 1985). Guilt and fear are both negative emotions and may leak through verbally by liars expressing more negative feelings and fewer positive feelings than truth tellers. 
Cross-cultural verbal deception

Lack of knowledge. Truth tellers, who have experienced an event, should have a more detailed mental representation of the event than liars, who just pretend to have experienced an event. Liars then face a dilemma when answering questions. They can express certainty and provide detail, because that will come across as honest (Bell \& Loftus, 1989). However, as mentioned above, they then run the risk that this information provides leads to investigators that they are lying, which is something liars would like to avoid. An alternative approach is therefore to express lack of knowledge when answering questions.

Expressing normality. Liars try to avoid looking suspicious. However, people also think that their state of mind shines through and will be immediately apparent to others (Granhag, Strömwall, \& Hartwig, 2007; Kassin \& Gudjonsson, 2004; Vrij, Mann, \& Fisher, 2006). This phenomenon could be explained by the illusion of transparency (Gilovich, Savitsky, \& Medvec, 1998), the belief that one’s inner feelings will manifest themselves to external observers. Therefore, in interview settings, liars may start to think that the alleged experiences they report may sound suspicious. To counteract this, they may emphasise the normality of their reported alleged experiences, as something that is not at all out of the ordinary. For example, "We decided to meet at the cafe in the morning like every day, we drink coffee, we eat, we talk in general, about the day, how it was”.

Interactive cues. When truth tellers are asked about a shared experience, they will probably do what people typically do when they discuss shared experiences: They will start to reconstruct the event jointly and are likely to interact with each other, sharing the telling of these experiences, comparing and correcting each other's recall. As a result, they are likely to interrupt and add information to each other's accounts while also correcting each other (Rajaram, 2011; Vrij et al., 2012). When liars are asked about their supposedly shared experiences a different response pattern may emerge. Liars typically prefer a 'keep it simple' approach (Hartwig, Granhag, \& Strömwall, 2007) and this will likely result in fewer 
Cross-cultural verbal deception

interactions between them. For example, one person may answer the question(s) and the other person may simply agree with what has been said, without adding interruptions or additions. Also, liars take their credibility less for granted than truth tellers (Granhag et al., 2007; Kassin, Appleby, \& Torkildson-Perillo, 2010). As such, liars will be more inclined to avoid doing or saying something that they think will leave a suspicious impression. Making corrections is a cue that people believe looks suspicious (Strömwall, Granhag, \& Hartwig, 2004; Vrij, Akehurst, \& Knight, 2006).

Interruptions, additions and corrections are speech utterances, but do not indicate what someone will say. In terms of what truth tellers may say, a joined recall of an event often leads to joint memory search typified by posing questions to each other, providing cues to each other and finishing each other sentences (Vernham \& Vrij, 2015; Vernham, Vrij, Leal, \& Mann, 2014). It may also lead to affirmations: Offering an explanation of what has happened. In contrast, liars' tendency to keep it simple may result in repeating and/or agreeing with what the other person has said.

We finally examined the use of sarcasm and jokes. Liars' aim is to satisfy interviewers, and they think they can achieve this by providing a detailed account (Nahari et al., 2014a). However, if they cannot provide lots of information they may try to do that in different ways, perhaps by introducing humour. The use of humour is a lubricant in social situations and can smooth interactions and increases credibility (Martineau, 1972; Meyer, 2000). The use of humour may serve another aim. Liars may consider the situation to be tense during the interview and, according to the relief theory, jokes are used to diffuse a potentially tense situation (Berlyne, 1972; Meyer, 2000).

\section{Culturally specific cues to deceit}


Cross-cultural verbal deception

Culturally specific cues to deceit can occur in two different ways. First, perhaps the difference between truth tellers and liars changes direction in different cultures. That is, to use the cue 'number of details' as an example, perhaps truth tellers provide more details than liars in one culture, but fewer details than liars in another culture. We do not expect this to happen. The expected differences between truth tellers and liars in verbal cues are based on a mixture of cognitive theory, liars' and truth tellers' strategies (impression management) and joint memory recall and we see no reason why these underlying processes will become apparent verbally in different ways in different cultures. Second, perhaps a verbal cue emerges as a cue to deceit in one culture but not in another. This is more likely to happen. For example, if interviewees in low-context cultures interact more with each other than interviewees in high-context cultures, interactive cues (cues 7 to 16 in Table 1) may become more diagnostic cues to deceit in low-context cultures due to the relative absence of these communication cues in high-context cultures in both truth tellers and liars (e.g. floor effect). This reasoning is similar to the explanation as to why in information-gathering interviews more verbal cues to deceit occur than in accusatory interviews: In accusatory interviews suspects say less than in information-gathering interviews, giving verbal cues to deception less chance to occur since words are the carriers of verbal cues to deceit (Vrij, Mann, Kristen, \& Fisher, 2007; Vrij et al., 2017b).

\section{Hypotheses}

We expect the British participants, compared to the Chinese and Arab participants, to provide more information, to express more feelings and to interact more with each other (Hypothesis 1)

We expect truth tellers, compared to liars, to provide more details and more checkable sources, to express more positive feelings, to include more interruptions, additions and 
Cross-cultural verbal deception

corrections, and to pose more questions to each other, providing more cues to each other, finishing each other sentences more and provide more affirmations (Hypothesis 2)

We expect liars, compared to truth tellers, to express more negative feelings, to express more lack of knowledge, to express normality more, to repeat each other more, to agree more with what the other person has said and to make more jokes (Hypothesis 3)

We expect the Veracity effect for the interactive cues to occur particularly in a lowcontext culture -British interviewees (Veracity X Ethnic Group interaction effect) (Hypothesis 4)

\section{Method}

\section{Ethics}

A favorable ethical review decision was given, prior to the research, by the relevant ethics committees of the two universities where the study took part.

\section{Participants}

A total of 306 participants (153 pairs) took part of whom 86 were male and 218 were female (two did not indicate gender). Their average age was $M=21.31$ years $(S D=3.79$ ) (two participants did not indicate age). The 153 pairs consisted of 49 British pairs, 48 Chinese pairs and 56 Arab pairs. The British and Chinese participants were recruited at a British university, the Arabs were recruited at an Israeli university. The British and Arab participants were British and Israeli citizens, whereas the Chinese participants were in the UK to study. There was no difference in the gender distributions between the three ethnic groups, $X^{2}(2, \mathrm{~N}=304)=4.53, p=.104$. Neither was the difference in age between the three ethnic groups significant, $F(2,300)=.73, p=.48$. During the interviews the pairs consisted of males only $(n=22)$, females only $(n=85)$ or mixed $(n=45)$ (one unknown pair). This distribution did not differ between the three ethnic groups $\left(X^{2}(4, \mathrm{~N}=152)=8.32, p=.080\right.$. 
Cross-cultural verbal deception

The current project is part of a larger project. In the other part of the project a model statement manipulation in a collective interview setting was examined (Vernham, Vrij, \& Leal, 2018). The 49 British pairs in the current study were part of a 67 pairs control group of the other study, which also included 18 pairs of non-British participants (not the Chinese and Arab participants of the current sample). In the control group of the other study no model statement was introduced.

\section{Design}

This experiment used a between-subjects design with Veracity (truth versus lie) and Ethnic Group as the two between-subjects factors. The 16 verbal cues presented in Table 1 were the dependent variables.

\section{Procedure}

The procedure for this experiment was derived from the procedures used by Stromwall, Granhag, and Jonsson, (2003) and Vrij et al. (2009, 2012). Participants were recruited via online advertisements, the university staff and student portals, and word of mouth. Each ethnic group was interviewed by an interviewer belonging to their ethnic group (British, Chinese and Arab) in their own language (English, Chinese and Arabic) and received the instructions in their own language. They also completed the questionnaires in their own language. All participants were told prior to signing up to the experiment that it was an experiment investigating the interactions occurring between friends and were required to sign up in pairs. Pairs were friends as this reflects real-life criminal networks. They were told that they would each receive $£ 8$ (the equivalent amount in Israel). The ethnic groups were recruited via separate advertisements. For example, there was an advertisement for ‘Arabic speaking pairs' and it was made clear that Arabic should be the native language of each participant. Native language was also recorded and checked on the pre-interview questionnaire. 
Cross-cultural verbal deception

Upon arrival at the laboratory, pairs of truth-tellers individually read and signed an informed consent form. They were then informed that the experiment was going to take place in a nearby restaurant and that a confederate would take them to the predetermined location. On route to the location, the confederate received a phone call to say that the experimenter was running late and therefore, as compensation, the pair of participants could buy something to eat or drink whilst they waited for the experimenter (participants were told to keep the receipt so that the money could be claimed back). The confederate informed the pair that he would return to collect them in 30 minutes if the experimenter had not arrived (at no point did an experimenter arrive to meet the pair of participants). After 30 minutes the confederate returned to the restaurant to take the pair back to the department. When the truth-tellers arrived back at the laboratory they were told that money and a data stick had been stolen whilst they were at lunch, and that, as suspects, they would be questioned about their activities in the restaurant.

Upon arrival at the laboratory, pairs of liars read and signed an informed consent form. They were then asked to steal $£ 10$ and a data stick (the equivalent amount in Israel) from a staff members' pigeon hole in the department and to return this to the experimenter in the laboratory, They were instructed to do this together and without raising suspicion. After returning the money and data stick to the experimenter, the pairs of liars were informed that the staff member had become aware of the theft and that they would be interviewed as to their whereabouts. They were instructed to prepare an alibi, which involved them telling the interviewer that they were having lunch together in a nearby restaurant at the time the money was stolen. Both the pairs of truth-tellers and pairs of liars were given as much time as they wanted to prepare themselves for their interviews but were not informed that they would be interviewed together in their pairs. 
Cross-cultural verbal deception

In the UK and Israel, truth tellers were escorted to one of three café/restaurants located within a five-minute walk from the department. Liars were instructed that their alibi was that they had been to one of these three restaurants. All liars reported that they knew the café/restaurant they were asked to lie about. Therefore, both liars and truth tellers discussed the same restaurants during the interview.

To motivate participants to perform well during the experiment, they were told that if they were believed by the interviewer they would, apart from earning $£ 8$ (the equivalent amount in Israel) be entered in a draw to win up to $£ 150$. However, if they were not believed they would not be entered in the draw and would be required to write a statement detailing their whereabouts during the time the money was stolen. We have not asked truth tellers whether they believed they were suspects in an actual, rather than a mock theft. We assume they did not, because none of the truth tellers asked whether they would be reported to the police in case they would not be believed. To ensure that the experiment was ethical and equal, all participants were paid $£ 8$ (the equivalent amount in Israel), entered in the draw and were told at the end of the experiment that the interviewer believed they were telling the truth.

Once the pairs of truth-tellers or liars indicated they were ready, they individually completed a pre-interview questionnaire. This questionnaire first asked participants to rate their friendship with their study partner on four 7-point Likert scales: friendliness (ranging from [1] strangers to [7] best friends), intimacy (ranging from [1] distant to [7] intimate), importance (ranging from [1] unimportant to [7] important) and trustworthiness (ranging from [1] distrusting to [7] trusting). The four questions were averaged into one cluster, friendliness (Cronbach's alpha $=.87$ ). Next, it asked participants to rate on 7-point Likert scales the quality (ranging from [1] very poor to [7] very good), usefulness (ranging from [1] pointless to [7] useful), sufficiency (ranging from [1] insufficient to [7] sufficient), and 
Cross-cultural verbal deception

thoroughness (ranging from [1] incomplete to [7] thorough) of their preparation discussion. The four questions were averaged into one cluster, preparation (Cronbach's alpha $=.94$ ).

Once the pair had individually completed the pre-interview questionnaire, they were taken to a forensic interview suite in which they were interviewed together and informed that they would be video- and audio-recorded. The interviewer was blind to the veracity status of the pairs and the hypotheses tested in the study. They were then asked nine questions, including "Can you tell me in as much detail as possible what you did while you were in the restaurant?", and "In relation to the front door, where did you both sit?" The interviewer did not state who in the pair had to answer each question. Once all nine questions had been asked, the pair left the interview suite.

Following participation, a post-interview questionnaire was completed individually. In this questionnaire, participants were asked to rate on a 7-point Likert scale from [1] not at all motivated to [7] extremely motivated, the extent to which they felt motivated to appear convincing during the interview. Once the post-interview questionnaire had been completed by both participants in the pair, they were each thanked for their time, fully debriefed, and provided with the opportunity to ask the experimenter questions.

\section{Coding}

Table 1 about here

All 153 interviews were transcribed, and the Chinese and Arab transcripts were subsequently translated into English by translators who were fluent in English. The English interview transcripts were each coded by a fluent British speaking rater who was blind to the hypotheses and veracity status of the pairs. A second coder, also fluent in English and blind to the hypotheses and veracity status of the pairs, rated 30 of the interview transcripts. Table 1 provides information about the 16 verbal cues that were introduced in the experiment and 
Cross-cultural verbal deception

gives definitions of each cue together with examples and the inter-rater reliability (Intra-Class Coefficient, ICC). As can be seen in Table 1, all ICCs were satisfactory.

Coding checkable details differed from how this has been done before (Nahari, Leal, Vrij, Warmelink, \& Vernham, 2014; Nahari et al., 2014a, b). Rather than counting the number of verifiable details, we counted the number of verifiable sources, that is sources that could ascertain verifiability of the details, such as named persons, CCTV footage, phone calls, text messages, bank statements and receipts. Thus, the sentence 'We saw my friend $\underline{\text { John }}$ when we had lunch in Zvi restaurant' contains four verifiable details (the underlined words) and one verifiable source (my friend John). In the current coding scheme, we only counted the verifiable source.

\section{Results}

\section{Motivation, preparation, and friendship}

Participants reported to have been motivated to perform well during the interview ( $M$ $=5.93, S D=137)$. A 3 (Ethnic Group) x 2 (Veracity) ANOVA revealed a significant Ethnic Group main effect, $F(2,292)=5.40, p=.005, \eta_{p}^{2}=.04$. Tukey post hoc tests showed that Chinese participants $(M=5.54, S D=1.47,95 \%$ CI $[5.26,5.83])$ were less motivated than British $(M=6.02, S D=1.46,95 \%$ CI $[5.75,6.29])$ and Arab participants $(M=6.15, S D=$ 1.12, 95\% CI [5.90,6.40]). However, the mean scores indicate that all subgroups were highly motivated. The Veracity main effect was also significant, $F(1,292)=4.72, p=.040, d=.23(-$ $.09, .55)$ and liars were somewhat more motivated $(M=6.09, S D=1.11,95 \%$ CI $[5.85,6.28])$ than truth tellers $(M=5.77, S D=1.58,95 \% \mathrm{CI}=5.52,5.96)$, However, the mean scores indicate that both truth teller and liars were motivated. The interaction effect was not significant, $F(2,292)=0.94, p=.393, \eta_{p}^{2}=.01$.

A total of 174 participants reported to have prepared themselves for the interview, most of them were liars $(n=114)$. Participants reported to have prepared themselves well for 
Cross-cultural verbal deception

the interview $(M=5.28, S D=1.40)$. A 3 (Ethnic group) x 2 (Veracity) ANOVA showed no significant effects for Ethnic Group, $F(2,168)=0.48, p=.618, \eta_{\mathrm{p}}^{2}=.01$ and Veracity, $F(1$, $168)=2.65, p=.105, d=.26(-.06, .57)$ and no significant Ethnic Group x Veracity interaction effect, $F(2,168)=2.90, p=.058, \eta_{p}^{2}=.03$.

Regarding friendship, truth tellers reported a stronger friendship with their fellow interviewee $(M=6.04, S D=0.89,95 \%$ CI $[5.87,6.18])$ than liars $(M=5.67, S D=1.03,95 \%$ CI $[5.50,5.80]), F(1,291)=11.65, p=.001, d=.38(.15, .61)$. In addition, the Ethnic Group main effect was significant, $\mathrm{F}(2,291)=8.80, p<.001, \eta_{p}{ }^{2}=.06$. Post hoc tests showed that Arab participants $(M=6.11, S D=1.03,95 \%$ CI $[5.93,6.29])$ reported a significantly stronger friendship with their fellow interviewee than Chinese participants $(M=5.56, S D=0.94,95 \%$ CI [5.36,5.74]), whereas British participants did not differ from either group, $(M=5.84, S D=$ 0.89, 95\% CI [5.66,6.04]). The Ethnic Group x Veracity interaction effect was not significant, $F(2,291)=0.34, p=.713, \eta_{p}^{2}=.00$.

To examine the possible effect of friendship on the hypotheses-testing analyses we carried out a MANCOVA with Ethnic Group and Veracity as factors, Friendship as a covariate and all variables listed in Table 1 as dependent variables. The multivariate effect for Friendship was not significant, $F(16,131)=.82, p=.667, \eta_{p}{ }^{2}=.09$. Also, when we re-ran the hypotheses-testing analyses without Friendship as a covariate, the same pattern of findings emerged. We thus concluded that Friendship had no effect on the results and so it was not included in the analyses.

\section{Hypotheses-testing: Details}

Tables 2 to 4 about here

A 3 (Ethnic Group) x 2 (Veracity) ANOVA with total details as dependent variable resulted in significant main effects for Ethnic Group and Veracity, see Tables 2 and 3. The interaction effect was not significant, $F(2,247)=1.91, p=.151, \eta_{p}^{2}=.03$. British 
Cross-cultural verbal deception

participants provided more details than Chinese and Arab participants, who did not differ significantly from each other, see Table 2 . In addition, truth tellers provided more details than liars, see Table 3. Finally, truth tellers were significantly more detailed than liars in each Ethnic Group. The effect size $(d)$ was substantial in each Ethnic Group, albeit the most substantial in the British participants, see Table 4.

A 3 (Ethnic Group) x 2 (Veracity) MANOVA with the subcategories of details (visual, spatial, temporal, auditory, action) as dependent variables resulted at a multivariate level in significant main effects for Ethnic Group, $F(10,286)=18.06, p<.001, \eta_{p}{ }^{2}=.39$ and Veracity, $F(5,143)=5.37, p<.001, \eta_{p}{ }^{2}=.16$ and in a significant Ethnic Group X Veracity interaction effect, $F(10,286)=2.07, p=.027, \eta_{p}{ }^{2}=.07$. At a univariate level, all Ethnic Group and Veracity effects were significant, see Tables 2 and 3. None of the interaction effects were significant, but trends emerged for three variables, visual details, $F(2,147)=$ 2.49, $p=.087, \eta_{p}^{2}=.03$, spatial details, $F(2,147)=2.44, p=.091, \eta_{p}{ }^{2}=.03$ and auditory details, $F(2,147)=2.63, p=.076, \eta_{p}^{2}=.03$. The trends are summarised in Table 4 .

The Ethnic Group main effects were caused by the British participants reporting more visual, spatial and action details than their Chinese and Arab counterparts, and reporting more temporal details than the Arab participants and more auditory details than the Chinese participants, see Table 2 .

Regarding the Veracity main effects, truth tellers reported more visual, spatial, temporal, auditory and action details than liars, see Table 3.

Regarding the Ethnic Group X Veracity interaction effects, for each ethnic group, truth tellers always reported more details than liars, but the strength of the effects differed between ethnic groups. The effects for visual and spatial details were the strongest for British participants and the weakest for Arab participants. Regarding auditory details, the effect was the strongest for Arab participants (and non-significant for British and Chinese participants). 
Cross-cultural verbal deception

Since the remaining dependent variables could be affected by the amount of information provided -the more details provided the more likely these variables will occur in statements- we included total details as covariate in the next analysis.

\section{Hypotheses-testing: Remaining variables}

A 3 (Ethnic Group) x 2 (Veracity) MANCOVA with total details as covariate and all fifteen remaining variables from checkable sources onwards listed in Table 1 as dependent variables revealed at a multivariate level significant main effects for Ethnic Group, $F(30$, 264) $=6.81, p<.001, \eta_{p}{ }^{2}=.44$ and Veracity, $F(15,132)=2.33, p=.005, \eta_{p}^{2}=.21$. The Ethnic Group x Veracity effect was also significant, $F(30,264)=1.66, p=.021, \eta_{p}{ }^{2}=.16$. The significant univariate main effects are presented in Tables 2 and 3.

The univariate effects for Ethnic Group showed significant effects for 11 out of 15 remaining variables (Table 2, variables from checkable sources onwards). Compared to the others, the Arab participants mentioned more checkable sources and emphasised normality more. Regarding the remaining variables, the British participants always included them more than the Chinese participants (except for finishing each other sentences) and often more than the Arab participants (except for interrupting one another, making additions and posing questions to one another). No differences between Chinese and Arab participants emerged for these variables except for the following variables which were more included by Arab participants: Interrupting one another, making additions and posing questions to one another. In sum, seven out of the 16 verbal cues examined (including number of details) emerged most frequently in British interviews and a further four cues emerged more frequently in British interviews than in one other ethnic group (see Table 2). This shows support for Hypothesis 1.

Regarding the Veracity factor, at a univariate level a total of four out of 15 verbal cues included in the MANOVA revealed a significant effect. Truth tellers reported more checkable sources than liars. Liars emphasised normality more, and made more affirmative 
Cross-cultural verbal deception

comments and jokes than truth tellers. In sum, we predicted ten verbal cues (including number of details) to emerge more in truthful than in deceptive interviews (Hypothesis 2), but only three of these (33\%) predicted differences emerged. This shows limited support for Hypothesis 2. We further predicted a further six verbal cues to emerge more in deceptive than in truthful interviews (Hypothesis 3) and two of these predicted differences (33\%) emerged. This shows also limited support for Hypothesis 3.

At a univariate level, only one interaction effect was significant: Interruptions, $F(2,146)=4.37, p=.014, \eta_{p}{ }^{2}=.06$. Table 4 provides the results for the Veracity effects in each of the three Ethnic Groups. Interruptions differentiated truth tellers from liars in Brits, but not in the Chinese and Arabs. To provide a total overview of the findings, we also examined the Veracity effects per Ethnic Group for the remaining four variables that revealed an overall Veracity main effect (Table 3). Table 4 reveals that other than interruptions also jokes differentiated truth tellers from liars in British participants, but not in Chinese and Arab participants, partially supporting Hypothesis 3. Affirmative comments also differentiated truth tellers from liars in British participants, but also in Chinese participants. Finally, checkable sources and emphasising normality differentiated truth tellers from liars in Arab participants but not in British and Chinese participants. In sum, there is no support for Hypothesis 4 that the Veracity effects would be most pronounced in British participants.

\section{Discussion}

In the present experiment, we examined differences between truth tellers and liars in one low-context culture (British interviewees) and two high-context cultures (Chinese and Arab interviewees). The findings are summarised in Table 5.

Table 5 about here

First, we found differences between the three ethnic groups in the number of details they reported. The British participants reported more details than the Chinese and Arab 
Cross-cultural verbal deception

participants. In low-context cultures a more explicit communication style is used than in high-context cultures, which explains this effect. Not only is speech more detailed in lowcontext cultures, but legal contracts also tend to be longer in these cultures (Liu, 2016). As reported in the Introduction, Taylor et al. (2014) found that spatial information was related to deception in different ways depending on the culture: It was indicative of deception in North African and Pakistani populations but indicative of truth in Arab and White British populations. In our analyses (not summarised in Table 5), the five categories of detail always occurred more in truthful than in deceptive statements for all three ethnic groups. In terms of spatial information, our findings supported Taylor et al. (2014) for British and Arab participants; the Chinese participants also responded similarly to the British and Arab participants.

Differences in verbal cues between the three cultures (cross-cultural cues) were generally substantial, because they emerged in 12 out of 16 cues that were examined. Most of the time the verbal cues emerged more frequently in the British participants than in the Chinese and Arab participants, reflecting the explicit nature of low-context communication, supporting Hypothesis 1.

Regarding the cues to deceit, we distinguished between ten verbal cues that we expected to emerge more frequently in truthful interviews (Hypothesis 2) and six verbal cues that we expected to emerge more frequently in deceptive interviews (Hypothesis 3). We found similar limited support for the truthful cues (three out of ten were significant) and for the deceptive cues (two out of six were significant). The little support for truthful cues was caused by the interactive cues, because the vast majority of them occurred as frequently in truthful as in deceptive accounts. This contradicts previous research in which such cues emerged most frequently in truthful accounts (Vernham \& Vrij, 2015). We cannot explain the Veracity null effects for the interactive cues. Null-effects can typically be explained by an 
Cross-cultural verbal deception

insensitive coding method, poor sample size or an experimental scenario that is unsuitable for such cues to arise. These explanations are inappropriate in the present context because crosscultural differences did emerge.

The limited support for the verbal deceptive cues follows a general pattern in verbal deception research, where verbal cues to deceit are typically weak (and weaker than verbal cues to truthfulness). This applies to the verbal veracity tool Reality Monitoring, where the only verbal cue to deceit -cognitive operations- received little empirical support (Masip, Sporer, Garrido, \& Herrero, 2005); and this also applies to recent research in which complications (cue to truthfulness), common knowledge details (cue to deceit) and selfhandicapping strategies (cue to deceit) are examined. Out of these three cues, complications emerged as the most diagnostic cue (Vrij, Leal, Jupe, \& Harvey, 2018; Vrij et al., 2017a).

The five cues to deceit that did emerge were not equally present in all three ethnic groups but appeared to be more dominant in one culture than in another culture (culturally specific cue to deceit). However, an erratic pattern emerged in which culture a cue was most dominant.

Thus, of the three types of cues we examined, (i) cross-cultural cues, (ii) cues to deceit and (iii) culturally specific cues to deceit), the cross-cultural cues did occur most frequently. The presence of cross-cultural cues could quickly lead to erroneous judgements of deceit. Observers belonging to low-context cultures probably expect many interactions between interviewees. The relative absence of such interactions contradicts such expectations. Expectancy violations are quickly perceived as suspicious (Bond et al., 1992), which could result in cross-cultural verbal communication errors, the mistaken interpretation of a cross-cultural verbal cue as a cue to deceit. Following the same reasoning, observers belonging to high-context cultures may perceive the many interactions between members of low-context cultures as suspicious. This could mean that in cross-cultural lie detection 
Cross-cultural verbal deception

contexts, in collective interviewing the same pattern of results may emerge as in interviewing individuals: Judgement accuracy tends to decrease when judgements are made across cultures (Taylor et al., 2014). To avoid such errors, practitioners could be made aware of the cultural differences through training. In addition, where possible, practitioners who belong to the same cultural group could be employed to conduct the interviews.

Three methodological issue merits attention. Strictly speaking the Ethnic Group factor was confounded as together with the interviewees' ethnic background, the interviewers' ethnic background was also manipulated. This confound issue is almost impossible to resolve and it becomes a question of what is the least serious confound. For example, to avoid the interviewer confound, all pairs could have been interviewed by the same interviewer who belongs to one of the three ethnic groups. This would have created other and -in our view more serious- confounds. In such a scenario, ethnic (dis)similarity between interviewer and interviewees and language (dis)similarity between interviewers and interviewees would have emerged as new confounds. To avoid all these confounds, we should have chosen an interviewer who does not belong to any of the three ethnic groups and who did not speak any of the three languages. This would have required an interpreter. The presence of an interpreter could have affected the results and it would have been premature to generalise the findings of these interpreter-present interviews to interpreter-absent interviews.

Compared to the English transcripts of the British participants, the English transcripts of the Chinese and Arab participants required as an extra step that the Chinese and Arabic text needed to be translated into English. This additional step may have resulted in some loss of information, but we believe that this potential loss has been very small. In a long consecutive interpreting study - in which the interpreter summarised the interviewee's answers - it was found that about $10 \%$ of information got lost through interpretation (Ewens et al., 2017). Long consecutive interpreting is a more difficult job than translating from a 
Cross-cultural verbal deception

transcript, so the potential loss of information is most likely considerably less than $10 \%$, and such a small loss probably would not have affected the results. However, in all research based on translations, conclusions can only be as strong as the translations are accurate.

We used a collective interview paradigm because it is a suitable paradigm to measure communication styles. However, collective interviewing is not a typical interview setting, interviewing people individually is much more common. Hopefully this article will encourage scholars to conduct more research in the important, but research-wise neglected, area of cross-cultural verbal deception.

\section{Acknowledgements}

This work was funded by the Centre for Research and Evidence on Security Threats (ESRC Award: ES/N009614/1) 
Cross-cultural verbal deception

\section{References}

Amado, B. G., Arce, R., Fariña, F. (2015). Undeutsch hypothesis and Criteria Based Content Analysis: A meta-analytic review. The European Journal of Psychology Applied to Legal Context, 7, 3-12. doi:10.1016/j.ejpal.2014.11.002

Bell, B. E., \& Loftus, E. F. (1989). Trivial persuasion in the courtroom: The power of (a few) minor details. Journal of Personality and Social Psychology, 56, 669-679. doi: 10.1037//0022-3514.56.5.669

Berlyne, D. E. (1972). Humor and its kin. In J. H. Goldstein \& P. E. McGhee (Eds.) The psychology of humor (pp. 43-60). New York: Academic Press.

Bernstein, B. (1966). Elaborated and restricted codes: An outline. Sociological Inquiry, 36, $253-261$.

Bond, C. F., \& Atoum, A. O. (2000). International deception. Personality and Social Psychology Bulletin, 26, 385-395. doi: 10.1177/0146167200265010

Bond, C. F., Omar, A., Mahmoud, A., \& Bonser, R. N. (1990). Lie detection across cultures. Journal of Nonverbal Behavior, 14, 189-205.

Bond, C. F., Omar, A., Pitre, U., Lashley, B. R., Skaggs, L. M. \& Kirk, C. T. (1992). Fishylooking liars: Deception judgment from expectancy violation. Journal of Personality and Social Psychology, 63, 969-977. doi:10.1037/0022-3514.63. 6.969

Copeland, L., \& Griggs, L. (1985). Going International. New York, NY: Random House, 1985.

DePaulo, B. M., Lindsay, J. L., Malone, B. E., Muhlenbruck, L., Charlton, K., \& Cooper, H. (2003). Cues to deception. Psychological Bulletin, 129, 74-118. doi: 10.1037/00332909.129.1.74

Ekman, P. (1985). Telling lies: Clues to deceit in the marketplace, politics and marriage. New York: W. W. Norton. (Reprinted in 1992, 2001 and 2009). 
Cross-cultural verbal deception

Ewens, S., Vrij, A., Leal, S., Mann, S., Jo, E., \& Houston, K. (2017). The effect of the presence and seating position of an interpreter on eliciting information and cues to deceit. Psychology, Crime, \& Law, 23, 180-200.

doi:10.1080/1068316X.2016.1239100

Gilovich, T., Savitsky, K., \& Medvec, V. H. (1998). The illusion of transparency: Biased assessments of others' ability to read one's emotional states. Journal of Personality and Social Psychology, 75, 332-346. doi: 10.1037/0022-3514.75.2.332

Granhag, P. A., Strömwall, L. A. \& Hartwig, M. (2007). The SUE technique: The way to interview to detect deception. Forensic Update, 88, January, 25-29.

Hall, E. T. (1976). Beyond Culture. Garden City, N.Y.: Anchor Press.

Hartwig, M., Granhag, P. A., \& Strömwall, L. (2007). Guilty and innocent suspects’ strategies during interrogations. Psychology, Crime, \& Law, 13, 213-227, doi: 10.1080/10683160600750264.

Kassin, S. M., Appleby, S. C., \& Torkildson-Perillo, J. (2010). Interviewing suspects: Practice, science, and future directions. Legal and Criminological Psychology, 15, 3956. doi: 10.1348/135532509X449361

Kassin, S. M., \& Gudjonsson, G. H. (2004). The psychology of confessions: A review of the literature and issues. Psychological Science in the Public Interest, 5, 33-67. doi: 10.1111/j.1529-1006.2004. 00016.x

Liu, M. (2016). Verbal communication styles and culture. In Oxford Research Encyclopedia of Communication. Oxford, UK: Oxford University Press. doi: 10.1093/acrefore/9780190228613.013.162.

Mann, S., Vrij, A., Shaw, D., Leal, S., Ewens, S., Hillman, J., Granhag, P. A., \& Fisher, R. P. (2013). Two heads are better than one? How to effectively use two interviewers to 
Cross-cultural verbal deception

elicit cues to deception. Legal and Criminological Psychology, 18, 324-340. doi: 10.1111/j.2044-8333.2012.02055.x

Martineau, W. H. (1972). A model of the social functions of humor. In J. H. Goldstein \& P.E. McGhee (Eds.), The psychology of humor (pp. 101-125). New York: Academic Press.

Masip, J., Sporer, S., Garrido, E., \& Herrero, C. (2005). The detection of deception with the reality monitoring approach: A review of the empirical evidence. Psychology, Crime, \& Law, 11, 99-122. doi: 10.1080/10683160410001726356

Meyer, J. C. (2000). Humor as a double-edged sword: Four functions of humor in communication. Communication Theory, 10, 310-331. doi:10.1111/j.14682885.2000.tb00194.x

Nahari, G. (2017). The applicability of the verifiability approach to the Real world. In P. Rosenfeld (Ed.). Detecting Concealed Information and Deception: Verbal, Behavioral, and Biological Methods. Amsterdam: Elsevier

Nahari, G., Leal, S., Vrij, A., Warmelink, L., \& Vernham, Z. (2014). Did somebody see it? Applying the verifiability approach to insurance claims interviews. Journal of Investigative Psychology and Offender Profiling, 11, 237-243. doi: 10.1002/jip.1417.

Nahari, G., Vrij, A., \& Fisher, R. P. (2012). Does the truth come out in the writing? SCAN as a lie detection tool. Law \& Human Behavior, 36, 68-76. doi: 10.1007/s10979-0119264-6

Nahari, G., Vrij, A., \& Fisher, R. P. (2014a). Exploiting liars' verbal strategies by examining the verifiability of details. Legal and Criminological Psychology, 19, 227-239, doi:10.1111/j.2044-8333.2012.02069.x

Nahari, G., Vrij, A., \& Fisher, R. P. (2014b). The Verifiability Approach: Countermeasures facilitate its ability to discriminate between truths and lies. Applied Cognitive Psychology, 28, 122-128. doi: 10.1002/acp.2974. 
Cross-cultural verbal deception

Oberlader, V. A., Naefgen, C., Koppehele-Gossel, J., Quinten, L., Banse, R., \& Schmidt, A. F. (2016). Validity of content-based techniques to distinguish true and fabricated statements: A meta-analysis. Law and Human Behavior, 1-63. doi: 10.1037/lhb0000193

Rajaram, S. (2011). Collaboration both hurts and helps memory: A cognitive perspective. Current Directions in Psychological Science, 20, 76-81. doi:10.1177/0963721411403251

Strömwall, L. A., Granhag, P. A., \& Hartwig, M. (2004). Practitioners' beliefs about deception. In P. A. Granhag \& L. A. Strömwall (Eds.), Deception detection in forensic contexts (pp. 229-250). Cambridge, England: Cambridge University Press.

Strömwall, L. A., Granhag, P. A., \& Jonsson, A. C. (2003). Deception among pairs: 'Let's say we had lunch together and hope they will swallow it'. Psychology, Crime, \& Law, 9, 109-124. doi:10.1080/1068316031000116238

Taylor, P. J., Larner, S., Conchie, S. M., \& Menacere, T. (2017). Culture moderates changes in linguistic self-presentation and detail provision when deceiving others. Royal Society Open Science, 4, 170128. doi: 10.1098/rsos.170128.

Taylor, P. J., Larner, S., Conchie, S. M., \& van der Zee, S. (2014). Cross-cultural deception detection. In P. A. Granhag, A. Vrij, \& B. Verschuere (Eds.), Detecting deception: Current challenges and cognitive approaches (pp. 175-201). Chichester, UK: John Wiley \& Sons.

Vernham, Z., \& Vrij, A. (2015). A review of the collective interviewing approach to detecting deception in pairs. Crime Psychology Review, 1, 43-58. doi: $10.1080 / 23744006.2015 .1051756$ 
Cross-cultural verbal deception

Vernham, Z., Vrij, A., \& Leal, S. (2018). Collective interviewing: The use of a model statement to differentiate between pairs of truth-tellers and pairs of liars. Manuscript under review.

Vernham, Z., Vrij, A., Leal, S., \& Mann, S. (2014). Collective Interviewing: A transactive memory approach towards identifying signs of truthfulness. Journal of Applied Research in Memory and Cognition, 3, 12-20. doi: 10.1016/j.jarmac.2014.01.001

Vrij, A. (2008). Detecting lies and deceit: Pitfalls and opportunities, second edition. Chichester: John Wiley and Sons.

Vrij, A., Akehurst, L., \& Knight, S. (2006). Police officers', social workers', teachers' and the general public's beliefs about deception in children, adolescents and adults. Legal and Criminological Psychology, 11, 297-312. doi: 10.1348/135532505X60816

Vrij, A., Jundi, S., Hope, L., Hillman, J., Gahr, E., Leal, S., Warmelink, L. Mann, S., Vernham, Z., \& Granhag, P. A. (2012). Collective interviewing of suspects. Journal of Applied Research in Memory and Cognition, 1, 41-44. doi: 10.1016/j.jarmac.2011.12.002

Vrij, A., Leal, S., Granhag, P. A., Mann, S., Fisher, R. P., Hillman, J., \& Sperry, K. (2009). Outsmarting the liars: The benefit of asking unanticipated questions. Law and Human Behavior, 33, 159-166. doi: 10.1007/s10979-008-9143-y.

Vrij, A., Leal, S., Jupe, L., \& Harvey, A. (2018). Within-subjects verbal lie detection measures: A comparison between total detail and proportion of complications. Legal and Criminological Psychology. doi:10.1111/lcrp.12126

Vrij, A., Leal, S., Mann, S., Dalton, G. Jo, E., Shaboltas, A., Khaleeva, M., Granskaya, J., \& Houston, K. (2017a). Using the Model Statement to elicit information and cues to deceit in interpreter-based interviews. Acta Psychologica, 177, 44-53. doi: 10.1016/j.actpsy.2017.04.011 
Cross-cultural verbal deception

Vrij, A., Mann, S., \& Fisher, R. (2006). An empirical test of the Behaviour Analysis Interview. Law and Human Behavior, 30, 329-345. doi: 10.1007/s10979-006- 9014-3

Vrij, A., Mann, S., Kristen, S., \& Fisher, R. (2007). Cues to deception and ability to detect lies as a function of police interview styles. Law and Human Behavior, 31, 499-518. doi: 10.1007/s10979-006-9066-4

Vrij, A., Meissner, C. A, Fisher, R. P., Kassin, S. M., Morgan III, A., \& Kleinman, S. (2017b). Psychological perspectives on interrogation. Perspectives on Psychological Science, 12, 927-955. doi: 10.1177/ 1745691617706515

Vrij, A., \& Nahari, G. (2016). Verbal lie detection. In P. A. Granhag, R. Bull, A, Shaboltas, \& E. Dozortseva (Eds), Psychology and Law in Europe: When West meet East (pp. 263-282). Boca Raton, Florida: Taylor \& Francis Group.

Vrij, A., \& Semin, G. R. (1996). Lie experts' beliefs about nonverbal indicators of deception. Journal of Nonverbal Behavior, 20, 65-80. doi: 10.1007/BF02248715

Vrij, A., Taylor, P. J., Picornell, I. (2015). Verbal lie detection. In G. Oxburgh, T. Grant, T. Myklebust, B. Milne (Eds.) Communication in Investigative and Legal Contexts: Integrated Approaches from Forensic Psychology, Linguistics and Law Enforcement (pp. 259-286). Chichester, UK: John Wiley \& Sons.

Vrij, A., \& Winkel, F. W. (1991). Cultural patterns in Dutch and Surinam nonverbal behavior: An analysis of simulated police/citizen encounters. Journal of Nonverbal Behavior, 15, 169-184. doi: 10./1007/BF01672219

Vrij, A., \& Winkel, F. W. (1992). Cross-cultural police-citizen interactions: The influence of race, beliefs and nonverbal communication on impression formation. Journal of Applied Social Psychology, 22, 1546-1559. doi: 10.1111/j.1559-1816.1992.tb00965.x 


\section{Cross-cultural verbal deception}

Table 1.

Coded variables: Definitions, Examples and Interrater Reliability

\begin{tabular}{|c|c|c|}
\hline Variable & Definition and example & ICC \\
\hline Visual details & $\begin{array}{l}\text { Information about what the participants saw (e.g. "We sat on } \\
\text { two blue chairs") }\end{array}$ & .99 \\
\hline Spatial details & $\begin{array}{l}\text { Information about the locations or spatial positions of people } \\
\text { and/or objects (e.g. "We were next to the toilets, behind the } \\
\text { bar") }\end{array}$ & .99 \\
\hline Temporal details & $\begin{array}{l}\text { Information about when the event happened or a description } \\
\text { of the sequence of events (e.g. "After } 20 \text { minutes of talking } \\
\text { our food arrived, so we then ate"), } \\
\text { Also includes giving the exact time or date (e.g. 'It was } 7 \\
\text { O'clock', 'It was Monday 5 5 January 2010) }\end{array}$ & .98 \\
\hline Auditory details & $\begin{array}{l}\text { Information about what the person heard, including } \\
\text { conversations with others (e.g. "We could hear the bell } \\
\text { chiming from the Guildhall whilst we talked about what we } \\
\text { were going to be doing after our undergraduate degrees) }\end{array}$ & .92 \\
\hline Action details & $\begin{array}{l}\text { Details about what the participant themselves did or what } \\
\text { their partner did (e.g. "We walked around and looked for } \\
\text { somewhere to sit"). }\end{array}$ & .97 \\
\hline $\begin{array}{l}\text { 1. Details (Visual, spatial, } \\
\text { temporal, auditory and action } \\
\text { details combined) }\end{array}$ & $\begin{array}{l}\text { Adding together the frequency of each type of detail across } \\
\text { all eight interview questions. Details were only coded once } \\
\text { throughout each interview; hence, the same information was } \\
\text { never coded more than once. }\end{array}$ & .98 \\
\hline 2. Checkable sources & $\begin{array}{l}\text { The participants either name or adequately describe a } \\
\text { person(s) who can verify where they were or provide } \\
\text { evidence as to where they were (e.g. "After a while my } \\
\text { roommate came over, he was riding a bicycle, his name is } \\
\text { Kihall", "I was texting my friend Dave, I can show you the } \\
\text { texts if you want" }\end{array}$ & .95 \\
\hline 3. Positive feelings & $\begin{array}{l}\text { Any positive descriptions about what the participant thought } \\
\text { (e.g. 'it was good', 'it was beautiful'), or any positive } \\
\text { descriptions about how the participant felt (e.g. 'excited', } \\
\text { 'happy'). }\end{array}$ & .99 \\
\hline 4. Negative feelings & $\begin{array}{l}\text { Any negative descriptions about what the participant thought } \\
\text { (e.g. 'it was horrible', 'it was disgusting'), or any negative } \\
\text { descriptions about how the participant felt (e.g. 'sad', } \\
\text { 'nervous'). }\end{array}$ & .91 \\
\hline 5. Lack of knowledge & $\begin{array}{l}\text { Participants say they did not see something or hear } \\
\text { something so cannot answer the question (e.g. 'I don't know } \\
\text { what we discussed', 'I can't remember') }\end{array}$ & .91 \\
\hline 6. Emphasising normality & $\begin{array}{l}\text { Participants emphasise that this is just a normal event that } \\
\text { they frequently do (e.g. "We were sitting and talking like we } \\
\text { do every day, we always sit and talk a lot", "It was just a } \\
\text { normal trip to the café to be honest" }\end{array}$ & .96 \\
\hline
\end{tabular}


Cross-cultural verbal deception

\begin{tabular}{|c|c|c|}
\hline 7. Interrupting one another & $\begin{array}{l}\text { One participant disrupts the other participant in the pair as } \\
\text { they are speaking and takes over the conversation. }\end{array}$ & .87 \\
\hline 8. Additions & $\begin{array}{l}\text { One participant in the pair provides new and different details } \\
\text { in response to what their partner has previously said. }\end{array}$ & .84 \\
\hline 9. Correcting one another & $\begin{array}{l}\text { One participant correcting information that their partner has } \\
\text { provided (without being prompted by the interviewer). }\end{array}$ & .98 \\
\hline $\begin{array}{l}\text { 10. Posing questions to one } \\
\text { another }\end{array}$ & $\begin{array}{l}\text { Participants question one another to check information, find } \\
\text { out information, or create discussions (e.g. 'Do you think it } \\
\text { was about } 25 \text { minutes before we ordered?', 'The food took } \\
\text { ages, didn't it?, 'Was there a diner by the door?') }\end{array}$ & .93 \\
\hline $\begin{array}{l}\text { 11. Providing cues to one } \\
\text { another }\end{array}$ & $\begin{array}{l}\text { Cross-cuing whereby one participant states something that } \\
\text { reminds their partner of additional information. Using } \\
\text { phrases such as 'I remember now', 'oh yeah and then...', 'I } \\
\text { can't believe I forgot about that' }\end{array}$ & .93 \\
\hline $\begin{array}{l}\text { 12. Finishing each other's } \\
\text { sentences }\end{array}$ & $\begin{array}{l}\text { One member of the pair starts saying something and then the } \\
\text { other member of the pair interrupts and finishes off their } \\
\text { sentence. }\end{array}$ & .84 \\
\hline 13. Affirmations & $\begin{array}{l}\text { Offering an explanation as to why they were doing } \\
\text { something or why something happened (e.g. 'We went to the } \\
\text { restaurant because we could get discount'). }\end{array}$ & .98 \\
\hline 14. Repetitions & $\begin{array}{l}\text { Participant repeats information that their partner has } \\
\text { previously said. }\end{array}$ & .91 \\
\hline 15. Agreements & $\begin{array}{l}\text { Participants in the pair supporting one another, agreeing } \\
\text { with one another, or backing-up/confirming details. Using } \\
\text { words such as 'yeah', 'exactly', 'indeed', 'very true', I agree' }\end{array}$ & .94 \\
\hline 16. Jokes /sarcasm & $\begin{array}{l}\text { One member of the pair making jokes against or criticising } \\
\text { the other member of the pair (e.g. one person making a joke } \\
\text { about the other person remembering a customer because } \\
\text { they fancied her) }\end{array}$ & .87 \\
\hline
\end{tabular}


Cross-cultural verbal deception

Table 2

Verbal Cues as a Function of Ethnic Group

\begin{tabular}{|c|c|c|c|c|c|c|c|c|c|c|c|c|}
\hline & \multicolumn{3}{|c|}{ British } & \multicolumn{3}{|c|}{ Chinese } & \multicolumn{3}{|c|}{ Arab } & $\mathrm{F}$ & $\mathrm{p}$ & $\eta_{p}^{2}$ \\
\hline Details (overall) & $117.79^{b}$ & $(49.28)$ & $107.24,129.30$ & $69.21^{\mathrm{a}}$ & (29.19) & $58.07,80.36$ & $75.75^{a}$ & $(44.14)$ & $65.44,86.07$ & 22.99 & $<.001$ & .24 \\
\hline Visual details & $65.90^{\mathrm{b}}$ & $(28.18)$ & $60.02,72.36$ & $37.74^{\mathrm{a}}$ & (15.94) & $31.51,43.98$ & $43.73^{a}$ & (24.59) & $37.96,49.50$ & 23.14 & $<.001$ & .24 \\
\hline Spatial details & $25.13^{\mathrm{b}}$ & $(11.76)$ & $22.82,27.77$ & $12.39^{\mathrm{a}}$ & (5.51) & $9.93,14.84$ & $15.70^{\mathrm{a}}$ & $(9.24)$ & $13.43,17.97$ & 29.49 & $<.001$ & .29 \\
\hline Temporal details & $11.38^{\mathrm{b}}$ & $(7.06)$ & $9.52,13.32$ & $11.06^{\mathrm{b}}$ & $(7.36)$ & $9.14,12.98$ & $4.94^{\mathrm{a}}$ & $(6.22)$ & $3.17,6.72$ & 15.58 & $<.001$ & .18 \\
\hline Auditory details & $5.34^{\mathrm{b}}$ & $(2.92)$ & $4.43,6.28$ & $2.48^{\mathrm{a}}$ & (1.17) & $1.55,3.42$ & $5.21^{b}$ & (4.69) & $4.35,6.08$ & 12.11 & $<.001$ & .14 \\
\hline Action details & $10.03^{b}$ & $(5.46)$ & $8.95,11.18$ & $5.54^{\mathrm{a}}$ & $(2.87)$ & $4.41,6.67$ & $6.16^{\mathrm{a}}$ & (3.43) & $5.12,7.21$ & 18.96 & $<.001$ & .21 \\
\hline Positive feelings & $0.63^{\mathrm{b}}$ & $(0.93)$ & $.31,68$ & $0.13^{\mathrm{a}}$ & $(0.39)$ & $.04, .38$ & $0.07^{\mathrm{a}}$ & $(0.32)$ & $-.03, .28$ & 4.47 & .013 & .06 \\
\hline Negative feelings & $1.04^{\mathrm{b}}$ & $(1.44)$ & $.52,1.10$ & $0.11^{\mathrm{a}}$ & $(0.31)$ & $-.04, .51$ & $0.27^{\mathrm{a}}$ & $(0.82)$ & $.10, .60$ & 4.02 & .020 & .05 \\
\hline Lack of knowledge & $1.35^{\mathrm{b}}$ & (1.38) & $.94,1.52$ & $0.21^{\mathrm{a}}$ & $(0.46)$ & $.01, .56$ & $0.17^{\mathrm{a}}$ & $(0.73)$ & $-.04, .46$ & 14.57 & $<.001$ & .17 \\
\hline Emphasising normality & $0.15^{\mathrm{ab}}$ & $(0.53)$ & $-.04, .34$ & $0.04^{\mathrm{a}}$ & $(0.20)$ & $-.15, .21$ & $0.34^{\mathrm{b}}$ & $(0.90)$ & $.17, .50$ & 3.15 & .046 & .04 \\
\hline Interrupting one another & $6.91^{\mathrm{c}}$ & (8.68) & $4.67,8.17$ & $1.08^{\mathrm{a}}$ & $(1.40)$ & $-.33,2.99$ & $3.48^{\mathrm{b}}$ & (4.79) & $2.13,5.15$ & 7.89 & $<.001$ & .10 \\
\hline Additions & $2.30^{\mathrm{b}}$ & $(2.48)$ & $1.09,2.38$ & $0.93^{\mathrm{a}}$ & (1.38) & $.65,1.87$ & $2.50^{\mathrm{b}}$ & $(2.47)$ & $2.16,3.27$ & 6.74 & .002 & .09 \\
\hline
\end{tabular}


Cross-cultural verbal deception

\begin{tabular}{|c|c|c|c|c|c|c|c|c|c|c|c|c|}
\hline Posing questions to one another & $3.91^{\mathrm{b}}$ & $(3.74)$ & $1.82,3.72$ & $2.29^{\mathrm{a}}$ & $(2.27)$ & $2.05,3.85$ & $4.49^{\mathrm{b}}$ & (3.71) & $4.09,5.72$ & 7.60 & .001 & .09 \\
\hline Providing cues to one another & $0.70^{\mathrm{b}}$ & $(1.21)$ & $.35, .78$ & $0.02^{\mathrm{a}}$ & $(0.14)$ & $-.11, .31$ & $0.09^{\mathrm{a}}$ & $(0.35)$ & $-.05, .33$ & 5.12 & .007 & .07 \\
\hline Finishing each other sentence & $0.74^{\mathrm{b}}$ & $(1.01)$ & $.38, .83$ & $0.48^{\mathrm{ab}}$ & $(0.77)$ & $.35, .78$ & $0.18^{\mathrm{a}}$ & $(0.39)$ & $.04, .43$ & 4.00 & .020 & .05 \\
\hline Agreements & $16.65^{\mathrm{b}}$ & (11.28) & $12.27,16.52$ & $4.06^{\mathrm{a}}$ & $(3.92)$ & $3.35,7.39$ & $3.67^{\mathrm{a}}$ & (4.73) & $2.66,6.33$ & 24.94 & $<.001$ & .26 \\
\hline
\end{tabular}

Note. Only mean scores with a different superscript differ significantly from each other $(p<.05)$

Note. Only variables that resulted in significant effects are reported. 
Cross-cultural verbal deception

Table 3

Verbal Cues as a Function of Veracity

\begin{tabular}{|c|c|c|c|c|c|c|c|c|c|}
\hline & \multicolumn{3}{|c|}{ Truth } & \multicolumn{3}{|c|}{ Lie } & \multirow[t]{2}{*}{$\mathrm{F}$} & \multirow[t]{2}{*}{$\mathrm{p}$} & \multirow[t]{2}{*}{$\mathrm{d}$} \\
\hline & M & (SD) & $95 \% \mathrm{CI}$ & $\mathrm{M}$ & (SD) & $95 \% \mathrm{CI}$ & & & \\
\hline Details (overall) & 113.03 & (59.08) & $104.40,123.49$ & 79.55 & (32.31) & $64.03,81.66$ & 22.15 & $<.001$ & $.70(.37,1.02)$ \\
\hline Visual details & 57.26 & $(30.54)$ & $52.72,62.65$ & 40.76 & $(17.97)$ & $35.83,45.69$ & 22.83 & $<.001$ & $.66(.32, .97)$ \\
\hline Spatial details & 20.80 & $(12.36)$ & $19.01,22.93$ & 14.60 & (7.37) & $12.64,16.53$ & 20.97 & $<.001$ & $.61(.23, .97)$ \\
\hline Temporal details & 10.44 & (7.92) & $9.12,12.17$ & 7.42 & (6.70) & $6.12,9.16$ & 7.60 & .007 & $.41(.04, .77)$ \\
\hline Auditory details & 5.34 & $(4.32)$ & $4.51,5.99$ & 3.47 & $(2.51)$ & $2.72,4.19$ & 11.55 & .001 & $.53(.16, .89)$ \\
\hline Action details & 8.05 & $(5.42)$ & $7.19,8.99$ & 6.37 & (3.12) & $5.52,7.31$ & 6.84 & .010 & $.38(.01, .74)$ \\
\hline Checkable sources & 0.70 & (1.17) & $.40, .80$ & 0.25 & $(0.49)$ & $.12, .51$ & 4.22 & .042 & $.50(.17, .82)$ \\
\hline Emphasising normality & 0.04 & $(0.20)$ & $-.10, .19$ & 0.33 & $(0.86)$ & $.16, .45$ & 5.71 & .018 & $.46(.14, .78)$ \\
\hline Affirmations & 3.03 & (3.19) & $1.81,3.01$ & 3.46 & (3.11) & $3.48,4.67$ & 14.16 & $<.001$ & $.14(-.45, .18)$ \\
\hline Jokes & 0.17 & $(0.50)$ & $-.12, .30$ & 0.41 & (1.18) & $.27, .69$ & 6.25 & .014 & $.26(.06, .58)$ \\
\hline
\end{tabular}

Note. Only mean scores with a different superscript differ significantly from each other $(p<.05)$

Note. Only variables that resulted in significant effects are reported. 
Cross-cultural verbal deception

Table 4

Verbal cues as a Function of Veracity and Ethnic Group

\begin{tabular}{|l|l|l|l|l|l|l|l|l|l|}
\hline & \multicolumn{3}{|c|}{ Truth } & \multicolumn{3}{c|}{ Lie } & F & P & \\
\hline Details (overall) & M & $(\mathrm{SD})$ & $95 \%$ CI & M & (SD) & $95 \%$ CI & & & \\
\hline British & 141.76 & $(53.80)$ & $123.84,159.69$ & 94.78 & $(30.94)$ & $77.21,112.33$ & 14.19 & $<.001$ & $1.08(.46,1.66)$ \\
\hline Chinese & 77.75 & $(26.05)$ & $66.17,89.34$ & 60.67 & $(30.18)$ & $49.09,72.26$ & 4.40 & .041 & $.61(.02,1.17)$ \\
\hline Arab & 88.41 & $(56.47)$ & $.72 .26,104.57$ & 63.09 & $(21.17)$ & $46.93,79.25$ & 4.94 & .031 & $.59(.05,1.12)$ \\
\hline Visual details & & & & & & & & & \\
\hline British & 80.29 & $(29.43)$ & $71.48,89.11$ & 52.09 & $(18.76)$ & $43.45,60.73$ & 16.14 & $<.001$ & $1.14(.52,1.72)$ \\
\hline Chinese & 43.21 & $(14.37)$ & $34.39,52.03$ & 32.28 & $(15.82)$ & $23.46,41.09$ & 6.28 & .016 & $.72(.13,1.29)$ \\
\hline Arab & 49.55 & $(31.14)$ & $41.39,57.72$ & 37.91 & $(13.86)$ & $29.75,46.07$ & 3.27 & .076 & $.48(-.06,1.01)$ \\
\hline Spatial details & & & & & & & & & \\
\hline British & 30.64 & $(12.80)$ & $27.16,34.11$ & 19.85 & $(7.77)$ & $16.45,23.26$ & 12.82 & .001 & $1.01(.40,1.59)$ \\
\hline Chinese & 14.47 & $(5.39)$ & $11.00,17.94$ & 10.31 & $(4.90)$ & $6.84,13.78$ & 7.85 & .007 & $.81(.21,1.38)$ \\
\hline Arab & 17.80 & $(11.36)$ & $14.59,21.02$ & 13.59 & $(5.97)$ & $10.38,16.80$ & 3.02 & .088 & $.46(-.07, .99)$ \\
\hline Auditory details & & & & & & & & & \\
\hline British & 6.02 & $(3.35)$ & $4.71,7.34$ & 4.68 & $(2.32)$ & $3.39,5.97$ & 2.67 & .109 & $.46(-.10,1.00)$ \\
\hline Chinese & 2.80 & $(1.44)$ & $1.48,4.11$ & 2.17 & $(1.93)$ & $0.85,3.49$ & 1.63 & .208 & $.37(-.21, .93)$ \\
\hline
\end{tabular}


Cross-cultural verbal deception

\begin{tabular}{|l|l|l|l|l|l|l|l|l|l|}
\hline Arab & 6.93 & $(5.64)$ & $5.71,8.15$ & 3.50 & $(2.63)$ & $2.28,4.72$ & 8.50 & .005 & $.78(.22,1.31)$ \\
\hline Interruptions & & & & & & & & & \\
\hline British & 4.57 & $(6.22)$ & $0.026,7.45$ & 9.15 & $(10.14)$ & $6.33,13.58$ & 5.14 & .028 & $.54(-.04,1.10)$ \\
\hline Chinese & 1.17 & $(1.49)$ & $(0.46,1.59)$ & 0.99 & $(1.33)$ & $0.56,1.70$ & 0.06 & .800 & $.13(-.44, .69)$ \\
\hline Arab & 4.41 & $(5.81)$ & $2.63,6.33$ & 2.55 & $(3.33)$ & $0.63,4.34$ & 2.24 & .141 & $.39(-.14, .92)$ \\
\hline Checkable sources & & & & & & & & & \\
\hline British & 0.71 & $(1.04)$ & $0.24,0.87$ & 0.12 & $(0.33)$ & $-0.04,0.58$ & 1.49 & .228 & $.77(.18,1.34)$ \\
\hline Chinese & 0.13 & $(0.34)$ & $-0.05,0.25$ & 0.17 & $(0.38)$ & $0.04,0.34$ & 0.69 & .412 & $.11(-.46, .68)$ \\
\hline Arab & 1.18 & $(1.49)$ & $0.69,1.58$ & 0.44 & $(0.64)$ & $0.03,0.92$ & 4.19 & .046 & $.65(.10,1.17)$ \\
\hline Emphasising normality & & & & & & & & & \\
\hline British & 0.04 & $(0.20)$ & $-0.19,0.29$ & 0.24 & $(0.72)$ & $-0.00,0.47$ & 1.05 & .310 & $.38(-.20, .93)$ \\
\hline Chinese & 0.00 & $(0.00)$ & $-0.09,0.08$ & 0.08 & $(0.28)$ & $0.00,0.17$ & 2.18 & .147 & $.40(-.17, .97)$ \\
\hline Arab & 0.07 & $(0.26)$ & $-0.25,0.42$ & 0.61 & $(1.20)$ & $0.26,0.93$ & 4.40 & .041 & $.62(.08,1.15)$ \\
\hline Affirmations & & & & & & & & & \\
\hline British & 4.58 & $(4.06)$ & $20.7,4.70$ & 4.86 & $(3.24)$ & $4.73,7.30$ & 7.30 & .010 & $.08(-.49,, 64)$ \\
\hline Chinese & 1.66 & $(1.64)$ & $0.20,2.27$ & 3.31 & $(3.60)$ & $2.70,4.77$ & 11.39 & .002 & $.59(.00,1.16)$ \\
\hline Arab & 2.87 & $(2.84)$ & $1.69,3.34$ & 2.33 & $(1.91)$ & $1.86,3.51$ & 0.08 & .775 & $.22(-.31, .74)$ \\
\hline
\end{tabular}


Cross-cultural verbal deception

\begin{tabular}{|l|l|l|l|l|l|l|l|l|l|}
\hline Jokes & & & & & & & & & \\
\hline British & 0.17 & $(0.48)$ & $-0.52,0.52$ & 0.65 & $(1.63)$ & $0.30,1.32$ & 4.41 & .041 & $.40(-.18, .95)$ \\
\hline Chinese & 0.09 & $(0.41)$ & $-0.17,0.38$ & 0.33 & $(0.82)$ & $0.04,0.59$ & 1.15 & .289 & $.37(-.21, .93)$ \\
\hline Arab & 0.25 & $(0.59)$ & $-0.12,0.48$ & 0.25 & $(0.97)$ & $0.02,0.62$ & 0.44 & .508 & $.00(-.52, .52)$ \\
\hline
\end{tabular}

Note. Only mean scores with a different superscript differ significantly from each other $(p<.05)$

Note. Only variables that resulted in significant effects are reported. 
Cross-cultural verbal deception

Table 5.

Schematic Summary of the Results

\begin{tabular}{|l|l|l|l|}
\hline Variable & Ethnic Group & Veracity & $\begin{array}{l}\text { Ethnic Group X } \\
\text { Veracity }\end{array}$ \\
\hline TRUTHFUL CUES & & & \\
\hline $\begin{array}{l}\text { Details (Visual, spatial, } \\
\text { temporal, auditory and action } \\
\text { details combined) }\end{array}$ & B > C and A & T > L & $\begin{array}{l}\text { British: T > L } \\
\text { Chinese: T > L } \\
\text { Arab: T > L }\end{array}$ \\
\hline Checkable sources & A > B and C & T > L & $\begin{array}{l}\text { British: - } \\
\text { Chinese: - } \\
\text { Arab: T > L }\end{array}$ \\
\hline Positive feelings & & & \\
\hline Interrupting one another (int) & B > A > C & & \\
\hline Additions (int) & B and A > C & & \\
\hline Correcting one another (int) & & & \\
\hline $\begin{array}{l}\text { Posing questions to one another } \\
\text { (int) }\end{array}$ & B and A > C & & \\
\hline $\begin{array}{l}\text { Providing cues to one another } \\
\text { (int) }\end{array}$ & B > C and A & & \\
\hline Finishing each other's sentences & B > A & & \\
\hline
\end{tabular}


Cross-cultural verbal deception

\begin{tabular}{|c|c|c|c|}
\hline (int) & & & \\
\hline Affirmations (int) & & $\mathrm{L}>\mathrm{T}$ & $\begin{array}{l}\text { British: } \mathrm{L}>\mathrm{T} \\
\text { Chinese: } \mathrm{L}>\mathrm{T} \\
\text { Arab: - }\end{array}$ \\
\hline \multicolumn{4}{|l|}{ DECEPTIVE CUES } \\
\hline Negative feelings & $\mathrm{B}>\mathrm{C}$ and $\mathrm{A}$ & & \\
\hline Lack of knowledge & $\mathrm{B}>\mathrm{C}$ and $\mathrm{A}$ & & \\
\hline Emphasising normality & $A>C$ & $\mathrm{~L}>\mathrm{T}$ & $\begin{array}{l}\text { British: - } \\
\text { Chinese: - } \\
\text { Arab: L > T }\end{array}$ \\
\hline \multicolumn{4}{|l|}{ Repetitions (int) } \\
\hline Agreements (int) & $\mathrm{B}>\mathrm{C}$ and $\mathrm{A}$ & & \\
\hline Jokes /sarcasm (int) & & $\mathrm{L}>\mathrm{T}$ & $\begin{array}{l}\text { British: T > L } \\
\text { Chinese: - } \\
\text { Arab: - }\end{array}$ \\
\hline
\end{tabular}

Note: (int) refers to interactive cues which only can be examined in collective interviews (first column only)

Note: $\mathrm{B}=$ British participants, $\mathrm{C}=$ Chinese participants, $\mathrm{A}=$ Arab participants; $\mathrm{T}=$ truth and $\mathrm{L}=$ lie

Note: > = significantly more than; - = non-significant difference (Ethnic Group X Veracity column only). Blank cells also indicate non-significant differences. 
Cross-cultural verbal deception 